\title{
CURRENT CHALLENGES OF DIGITAL TECHNOLOGIES
}

This contribution deals with questions on the relationship between reality and virtual reality. It focuses on the problem of shaping an individual's identity in a digital, online environment and, in this context, identifies a retrospective impact on the real person's identity. An effort will also be made to name selected problems related to the topic and to point out some risks that the online environment introduces to the field of self-perception, especially in regard to interpersonal relations. As a result, attention is drawn to changes in the value system that are related to the explored questions.

Keywords: identity, reality, virtual reality, digital online environment

\section{Introduction}

The aim of this contribution is to answer certain questions on the relationship between reality and virtual reality. It focuses on the problem of shaping an individual's identity in a digital and online environment, and, in this context, identifies the retrospective impact on the real identity of a person. In addition, an effort is made to identify selected problems related to the given topic and to highlight the risks which an online environment brings to the field of self-perception, and especially to the field of approaching relations between people. Ultimately, attention is brought to focus on changes in the value system that are related to the problems in question.

\section{The question of forming an individual's identity}

Questions on the relationship between man and society have been evolving since time immemorial, as have questions on the subject of social interdependence in human behavior. Man is always trying to realize his potential in a certain relationship. At the beginning there is a relationship, as stated by M. Buber [1], and the relationship is reciprocity: „The simultaneous coexistence of several persons in a mutual relationship is the essential requisite of human existence" [2, p. 30]. An individual can fully realize their social essence only in society, in close association with other groups and their members. Because man is a man thanks to contact with others, the emphasis placed on the necessity of these bonds and relationships is obvious. L. Hanus [3, p. 88-90] writes that the awareness of a common biological origin is the reason for mankind's solidarity. To be a human being means to be descended from others-that is, we are woven on the looms of others' lives. When it comes to the birth of man, the company participates physically as well as spiritually. First, the human being grows in the maternal womb and, later, he becomes a part of the social womb. This is his so-called second or social birth. Within the relational framework of an individual and society, each individual is unique, differing from others in his feelings, thoughts, experiences, and actions. As N. Elias notes [2, p. 85], the individual is a being for itself and-at the same time-for others, and all together they create societies with variable structures. No one would survive without society or learn to talk, think, love, or behave as a person. However social cohabitation of people is not always harmonious. It is often accompanied by tension, excited emotions, and conflicts. For individuals, cohabitation represents a network of interdependencies with its own rules. In the course of social processes, a human identity is created. Of course, the processes of identity construction are different in particular areas of life. Building an identity-understood as the survival of uniqueness, authenticity, and consistency of man in space and time-publicly or privately is a challenging task that every person must necessarily face. There are many factors involved in the process of identity creation and development, and various studies are being conducted in this area to identify individual variables involved in the process. It is indisputable that this is a dynamic process, connecting the personal and the social world. Identity is

\footnotetext{
* ${ }^{1}$ Andrea Leskova, ${ }^{2}$ Hubert Jurjewicz, ${ }^{3}$ Patrik Lenghart, ${ }^{4}$ Peter Bacik

${ }^{1}$ Department of General and Applied Ethics, Faculty of Arts, Constantine the Philosopher University, Nitra, Slovakia

${ }^{2}$ College of Saint Elizabeth, Morristown, NJ, USA

${ }^{3}$ Department of Journalism, Faculty of Arts, Constantine the Philosopher University, Nitra, Slovakia

${ }^{4}$ Department of Arrhythmias, SUSCCh a.s., Banska Bystrica, Slovakia

E-mail: aleskova@ukf.sk
} 
not predetermined by the very existence of an individual, but rather is created and shaped as a result of various social experiences. [4] According to G. H. Mead [5] - one of the founders of symbolic interaction and role theory-each human being is creating an idea of himself as he interacts with other people. We build the selfrelationship only through our relationship with other people. In Mead's concept, a man acts as an active being, but, at the same time, as a product of social relations. Man is born in the company of others and this company is approached by Mead at the level of communication. Communication consists of the exchange of significant symbols, which are based on certain intentions of one of the participants and which inform the corresponding intentions of the other participant within the interaction process. Questions on the subject of the formation of the identity of an individual are becoming more and more insistent, mostly during the development of new technologies, internet and electronic social networks. K. Fichnova and B. Sramova [6, p. 11] point out two component self-concepts that have formed within the internet environment: in electronic communication, self-perception is significantly stronger, while perception of the environment is weakened. The external perception of the self (as others perceive it) is significantly lower in electronic communication. Also noteworthy is the depressing effect of deindividuation on persons utilizing the internet for communication. Internet communication does not dismantle communication barriers, but rather strengthens them. Deindividuation reinforces stereotypical behavior and the consequences of our behavior in the internet environment are distinct from those occurring in real life. As noted by B. Malik [7], virtual identity represents a special case of identity, where its peculiarity is formed without the limitations of the world of phenomena. Its distinguishing features are incorporeity and a detachment from locality boundaries. In virtual worlds, people are not present in all their complexity. Individuals acting in an online environment do not enter into specific relationships in their specific certainty; their relations to others lack the personal character present in a physical environment. Universal virtuality (which follows the thinking that every reality is artificial, having been created by man) has been, is, and always will be present in the human world because it determines its existence. Yet according to Miczka [8, p. 232-233], particular virtuality is becoming increasingly important, having developed alongside digital technology which is based on the revelation of the artificial, conventional character of the human world. Multimedia allows each person to perceive something else and, above all, allows him to decide what he sees and perceives. Particular virtuality relies on adapting to the needs of perception. In this context it is worth mentioning Baudrillard's concepts of simulacrum (a copy without an original) and simulation as they relate to the mass reproduction and reproducibility which characterizes our electronic media culture. We live in a world which changes exceedingly fast and a component of this change is electronic media. The era of simulation, claimed J. Baudrillard [9, p. 2], begins with a liquidation of all referential points. Hyperreality is being created and there is no independent point of reference. It is no longer a question of imitation, nor of reduplication, nor even of parody. It is rather a question of substituting signs of the real for the real itself. Differences between real and imaginary, or true and false, are becoming more and more problematic.

\section{The era of new information and communication technologies and risk context}

Information and communication technologies are growing at an increasing pace. The number of people using the internet worldwide is burgeoning rapidly. The impact of information technology and media is more powerful, their quasi-ubiquity and continual necessity are reflected in the everyday life of individuals in society. P. Rankov [10, p. 18] notes that the multimedia computer and the computer network dissolve the traditional boundaries between different kinds of media. The internet, which is connected with the beginning of the era of decentralized and interactive mass media, is both public and private. The divisions of private, public, and labor spheres are disappearing. We can communicate with anyone from anywhere. Different kinds of communication can take place in the same environments or spaces. Similarly, there is a time shift in recording reality which denies the boundaries between past and present. According to Rankov [10, p. 82], the internet is also a medium which ensures anonymity: „This anonymity transforms network users into a specific type of virtual mass or crowd, likewise the audience of mass media has been a specific type of mass or crowd." Anonymity can create room for greater individual resolution or courage in communication; it can promote exuberance, vulgarity, or even an interchange of standards. The question of the individual's identity seems to be particularly complicated. The possibility of virtual identity makes people more free. In virtual communication, you can easily become someone else or become even more yourself. In such communication, all connected parties are equal and are equally deprived of all barriers and limitations. We agree with Rankov [10, p. 83], who prophetically asks whether such an experiment with our own identity and the fragmentation of our personality will not necessarily lead to problems and failures. Similar concerns related to the problem of the internet are also raised by Eco [11]. Information is spread through a wide variety of different and independent channels-the system is headless, uncontrollable, and everyone is talking with everyone. However, as noted by the author, the following points should remain true in the years ahead: 1 . telematic networks will remain a tool for the young and an educated elite and young people; 2. it is not given that these networks will remain headless and without centralized control; 3 . the tremendous amount of information that these networks offer might necessarily lead to censorship due to network overload [11, p. 66]. 
Following the previous points, it is necessary to emphasize the fact that the expansion of the tools of mass communication in society is dependent not only on the existence of certain social assumptions but also on the possibility of the tool itself becoming a source of social change. M. McLuhan is best known for his thesis, "The Media is the message," meaning that it is the media that shapes and controls the extent and form of human association and action. The content or uses of such media are as diverse as they are successful in shaping the form of human association. It is definitely too specific to say that the "content" of any medium blinds us to the character of the medium [12, p. 130]. According to McLuhan, the medium is everything that intensifies and broadens the possibilities of man for taking possession of the surrounding world. Every new medium, every new „extension“ of man, and every technology brings a new scale to the life of man, and this scale is itself a message which tells us more about man and society, as noted by J. Jirak and B. Köpplova [13, p. 40]. The message of each medium or technology is comprised of the change of scale or pace which have been incorporated into human affairs. In the communication process, the message transmitted by the communication itself may be secondary, and the medium itself may become decisive. In this way, the medium represents a message independent of its content, and thus the message itself. Even though McLuhan was reflecting on the corporation's fascination with technology, he was constantly searching for the possible foundations of a new universal society of technological culture. McLuhan recognized that the first step towards liberation from the impact of technology lay in a correct understanding of media messages. If we understand that the medium changes the proportion of senses involved in our perception of the world and that every new technology creates a new environment, we will be able to use these transformations for our own benefit.

As previously mentioned, we live in the era of new information and communication technologies, primarily invented to simplify or facilitate people's lives or improve the quality of life. The paradox of this new era-the so-called era of the Information Society-is the fact that communication is not considered as an interaction of one individual with another, but rather as an interaction of the individual with technology, as aptly noted by P. Rankov [10, p. 24]. Nowadays a person needs to be informed and to inform. The individual needs „to be updated“ as they face the increasing demands of handling new technologies. We quite often associate our independence, importance, and even freedom with the feeling and status of being „online“-and therefore with our availability through mobile and networked technologies. J. Meyrowitz [14, p. 259] compares the Information Society-with respect to the influence of electronic media on social interactions and the merging of social roles-to hunter/gatherer society. Our technologically advanced developmental stage allows us to collect information rather than food, and like hunters and gatherers who take it for granted that there is plenty of food "somewhere out there" just waiting to be gathered and hunted for immediate consumption, we are also moving closer to a „company nourished by information." The world is permeated by media and media are shaping our perception of the world in more or less obvious ways. According to B. Malik [7], the infinite spaces of virtual reality and virtual space are open to us thanks to information technologies where we are able to avoid physical contact and the necessity of mutual compromises. It is necessary to recognize the serious problem inherent in the withdrawal of man from localized, interpersonal bonds, in which he has always been situated as „someone"-with a permanent and individual name, face, and position developed over an extensive period of time. In a virtual environment, we are not compelled to learn how to get along with those we dislike and those who differ significantly from us. We are not required to clarify things with them or to confront our differing points of view. Within the environment of the internet, we tend to search out and create virtual contacts with individuals similar to us and allow them to confirm our identity. This environment appears much simpler in comparison with physical space, where we are often required to live in a tight circle of people we did not choose as neighbors. In a physical environment, a person is often forced to communicate and to be quite careful about what he says or does. A typical feature of an online environment is the individual's self-presentation and its related monologue, while the others add their comments, opinions, attitudes or „likes.“ In this respect, it is worth noting the opinion of contemporary American sociologist R. Sennett, who believes that if an individual approaches everything with an emphasis on his own identity, the consequences consist not only of the destruction of public life but also the decomposition of the private sphere (given that human relations are deeply damaged by a constant emphasis on our own personality [15, p. 180].

As technology has spread through our society, new behaviors and new ways of working have emerged. For example, few would have predicted the impact of technology on news reporting; an impact that has led to a new enfranchisement for citizens. Such changes necessarily affect the structures of a society and new or transformed institutions emerge [16]. Learners of all ages are also exhibiting new behaviors as a result of ubiquitous high functioning technologies. Changes may be relatively mundane, such as replacing the school folder with a memory stick, or more profound, as when learners voluntarily seek out expertise beyond the traditional classroom. Though these developments are not necessarily transformational, there are very real changes in behavior that have resulted from the exponential change in both the functionality and the cost of technology [17].

The question, therefore, is how do we take advantage of these new behaviors for the benefit of education? There is a need to make a realistic assessment of what technology can and cannot do to reach a plateau of productivity when the technology consistently delivers to realistic goals. So what is the way forward for education in this digital world? There are broadly three strategies: A minimum emphasis on technology - not a comfortable option 
in the context of digital inequity [18]; Getting technology to serve the system - identifying how technology supports the current business of education to good effect; or Merge and evolve allowing ourselves to adapt and respond to the possibilities from technology through innovation. Digital technologies are already requiring us to think differently about how learners learn and how teachers teach. From this perspective, we need to think about how schools or learning ecologies are organized, including the role of technology to support meaningful student achievement. But any innovation must first and foremost have an educational purpose, and that purpose should be to improve the outcomes for learners of any age because through learning people can live happier, healthier, more productive lives. The consensus is that for formal education a skilled teaching workforce is the key to success [19]. The following section details a growing body of research to assess in more detail the relationships between the digital, learning and educational worlds.

There are still some who would argue that the value of digital technologies for learning is at best unproven. However, there is now a growing body of evidence detailing the very real impact of technology on both formal and informal learning. For clarity, that evidence will be presented here under two headings: • impacts that bring about changes in behavior at learner, teacher and school level $\cdot$ those that bring about changes in academic performance. Much, but not all of the former, relies on formal and informal observation. Evidence on academic performance involves measurement of impact with statistically verifiable results and clear associations between the process and outcomes of that learning process [20].

There is a vast array of evidence related to behavioral changes when working with digital technologies. Here two areas of impact have been highlighted to represent this corpus of evidence. These are: - readiness for learning - integration of learners into the educational process. Readiness for learning: Learner performance in schools is a product of the characteristics of individual learners and the opportunities to learn provided not only by the school but also the home. Technology can enable the learner to fully benefit from formal education. At the school level, strategies may include the efficiencies in the monitoring of behavior to reduce persistent absenteeism, a factor in academic underachievement [21]. Students are different, but a lot of educational material is not. Schools are still using materials developed decades ago, but today's students come to school with very different experiences than those of 20 or 30 years ago. They think and work very differently as well. Institutions wanting to adapt to student needs should identify new learning models that are engaging to younger generations. Similarly, new as well as traditional assessment is required - problem orientated curricula as well as standardized testing [22].

The extent to which learners and their teachers have access to digital technologies at school and at home impacts on the educational experience that can be provided. While surveys show technology home access is high it is not universal. This is a concern, as where home technology is available it is proving an important part of the learning process. There is, then, an equity issue for those children who are disenfranchised by the lack of resource. Socio-economic factors are significant correlates of the level of e-access. Individual differences in e-access are related to both structural and individual learner factors. Use of technology in schools takes the form of an inverted u-function. In schools with scores at either end of the continuum of performance, pupils in receipt of free school meals or English as an additional language tend to make less frequent use of technologies for learning [23]. User e-Maturity: The level of skill, confidence, and knowledge learners have when using digital technologies will impact on the quality of their use of the technology. While most learners express very positive attitudes towards technology for learning and are confident users, there are skills gaps. Individual differences including attitudes towards school and using technologies for learning and access to, and use of, technologies for learning at home are key to the development of e-maturity [24].

In seeking to integrate technology into education, it is important to identify the technological trends and the challenges in the short and medium term. The six emerging technologies or practices that are likely to enter mainstream within five years are: - Mobile technologies are currently establishing themselves in schools while cloud computing is already a part of higher education. - Early adopters are already looking to use geo-coded data and personal webs. The former are central to satellite navigation systems but are entering the classroom through applications such as Google Earth. Students are now able to locate and date-stamp their own images. - Two technologies yet to have an educational impact are semantic-aware applications and smart objects, which have yet to gain a foothold in an educational context. These technologies have the potential to change educational practice, just as they are changing the world of work, but many of these technologies represent challenges to staff expertise and practice; [25]

The current demand for more research in education is predicated on the perceived need by policymakers for research of higher quality and greater utility than was previously available "One of the things most astonishing to posterity about our times will not be how much we understood but how much we took for granted.” [26, p. 20] It is imperative to develop concepts, theories and rigorous and appropriate methodologies to provide a robust evidence base and understanding of the impact of digital technologies on the educational process. There is a continuing need to identify, promote and support good practice and models of change to produce sustainable change. There remain many unanswered questions as to the role and value of digital technologies for learning. Questions such as the following: • What will be the impact of a technologically-maturing population on teacher practice and performance? [27] - What is the longterm impact of technology-rich learning? There have been few 
longitudinal studies. - How does exposure to and use of ICT in school affect future employment? - Do some learners gaining more from the use of digital technologies than others? And why? - What is the impact of formal digital literacy teaching in schools? - Should and how can we integrate or advantageously exploit the raft of personal technologies that dominate students' out of school lives into the classroom?

\section{Conclusion}

Self-idealization in an online environment-that is, hiding or camouflaging, creating a false identity, losing one's scruples or moral barriers, the trivialization of the principle „to show consideration for others," shifting from the classical rules relevant to real communication, and the limitation of social relations to the world of internet-belongs to the darker side of human experience in that environment. However, we cannot forget the indisputable advantages and benefits of a digital, online environment, as well as the fact that it is primarily the domain of the young. This necessarily invokes the inevitable debate in the field of scientific theory and research practice on the future of our offspring and our society.

Some research provides recommendations to empower parents to set limits without feeling intimidated. "The most effective parenting style in helping children deal with digital technology is an authoritative style....of parents setting firm limits." They acknowledge that in today's community, parents "feel less capable of establishing limits." Some parents secretly welcome their teens' constant involvement in cyber media as a form of babysitting that lessens their demands for parental attention. I think we can all agree that any parent who seeks to save time in this fashion will eventually confront more serious challenges in dealing with their child's overexposure. Today's parents are often unwilling to adopt an authoritative position because they don't want to deal with their children's tantrums or to be compared unfavorably to their children's friends more reasonable parents.

If familial bonds are strong, a collaborative effort should be made to create a formal understanding between parents and teenage children that include terms binding on ALL family members such as technology free meals and designated times on family vacations.

\section{References}

[1] BUBER, M.: You and Me (in Czech). Mlada fronta, Praha, p. 108, 1969.

[2] ELIAS, N.: Society of Individuals. An Outline of a Theory of Civilization (in Slovak). Kalligram, Bratislava, p. 256, 2006.

[3] HANUS, L.: Man and Culture (in Slovak). LUC, Bratislava, p. 311, 1997.

[4] The topic of religious existentialism and literature attracts much attention today, largely in relation to the ideas of Søren Kierkegaard. See: TAVILLA, I; KRALIK, R. \& MARTIN, J. G.: A brief recollection of Kierkegaard's testimony on reformation 500th anniversary. Xlinguae, 11(1), 354-362, 2018; VALCO, M.: Kierkegaard's 'Sickness unto Death' as a Resource in our Search for Personal Authenticity. European Journal of Science and Theology, 12(1), 97-105, 2016; VALCO, M. \& VALCOVA, K.: The Epistemological Challenge of Kierkegaard's Truth is Subjectivity Principle. Communications - Scientific Letters of the University of Zilina, 17(2), 103-108, 2015; VALCOVA, K., PAVLIKOVA, M. \& ROUBALOVA, M.: Religious Existentialism as a Countermeasure to Moralistic Therapeutic Deism. Communications - Scientific Letters of the University of Zilina, 18(3), 98-104. 2016; AMBROZY, M., KRALIK, R. \& MARTIN, J. G.: Determinismo vs Libertas: Algunas Implicaciones Etico-Sociales. Xlinguae, 10(4), 48-57, 2017; PAVLIKOVA, M.: Reading Auden as a Resource for Existential Reflection in a Society with Technocratic and Hedonistic Tendencies. Communications - Scientific Letters of the University of Zilina, 19(1), 39-43, 2017; TURCAN, C.: Rousseau and Kierkegaard Authenticity of Human Existence. European Journal of Science and Theology, 13(1), 5-13, 2017; KRALIK, R.: Kierkegaard's Interpretation of Faith. Xlinguae, 10(3), 37-44, 2017; KONDRLA, P. \& REPAR, P.: Ontological Consequences of the Ethics of Technology. Communications - Scientific Letters of the University of Zilina, 19(1), 19-24, 2017; PAVLIKOVA, M.: Kierkegaard's understanding of man and society. Xlinguae, 11(1), 323-331, 2018; MAHRIK, T., PAVLIKOVA, M. \& ROOT, J. Importance of the incarnation in the works of C.S. Lewis and S. Kierkegaard. European Journal of Science and Theology, 14(2), 43-53, 2018.

[5] MEAD, H. G.: Mind, Self and Society. University of Chicago Press, Chicago, p. 401, 1967, 1st ed. Chicago, 1934.

[6] FICHNOVA, K. \& SRAMOVA, B.: Identity and its Construction in Adolescents with Selected Features of Creative Personality (in Slovak). FICHNOVA, K. (Ed.): Identity and Mass-communication (in Slovak), UKF, Nitra, p. 9-46, 2010; BOCANOVA, M \& SLOBODOVA-NOVAKOVA, K. Addressing the issues of poverty and social exclusion of the city's inhabitants. European Journal of Science and Theology. 14(4), 85-93, 2018. 
[7] MALIK, B.: Change of Model of the Constitution of a Man's Personal Identity in the Post-Literary Era and its Impact on the Status of a Citizen (in Slovak) [online], Procceding of conference Kultura medii: su media mimo moralky?, 2013. Available: http:// www.noveslovo.skcZmena_modelu_konstituovania_osobnej_identity_cloveka_v_postliterarnej_dobe_a_jej_dopad_na_status; BINETTI, J. M., SLOBODOVA-NOVAKOVA, K. \& PAVLIKOVA, M.: “¿Multiculturalismo o feminismo? La discusion en torno al uso del velo integral”, Xlinguae, 11(2), 22-32, 2018.

[8] MICZKA, T.: Bifurcation or Transversality? The Relationship between Reality and Fiction in Digital World (in Slovak). KARUL, R. \& PORUBJAK, M. (Eds.): Reality and Fiction (in Slovak) 231-237, 2009; GOGORA, A.: Digital Humanities and Philosophy A Problem of Digital Research. World Literature Studies, 8(3), 104-114, 2016.

[9] BAUDRILLARD, J.: Simulacra and Simulation. Ann Arbor The University of Michigan Press, 1994. Originally published in French by Editions Galilee, 1981.

[10] RANKOV, P.: Information Society (in Slovak). LCA Publishers Group, Levice, p. 174, 2006; LENOVSKY, L, BINETTI, M. J. \& JANIKOVA, M. Ambivalence in interpretations of multiculturalism as a problem of forming the ethics-axiological foundations in an integrated society. European Journal of Science and Theology. 14(4), 49-58, 2018.

[11] ECO, U.: Five Reflections on Morality (in Slovak). Kalligram, Bratislava, p. 96, 2004.

[12] DURHAM, M. G. \& KELLNER, D. M.: Media and Cultural Studies. Blackwell Publishers Ltd, Oxford, UK, 2001.

[13] JIRAK, J. \& KOPPLOVA, B.: Media and Society (in Czech). Portal, Praha, p. 207, 2003.

[14] MEYROWITZ, J.: Everywhere and Nowhere. The Influence of Electronic Media on Social Behavior (in Czech). Karolinum, Praha, p. 344, 2006.

[15] SUBRT, J., et al: Contemporary Sociology IV (Current and Everyday) (in Czech). Karolinum, Praha, p. 384, 2010.

[16] MORRIS, N. P., LIVES, S. \& ELSTON, C.: First Time MOOC Provider: Reflections from a Research-Intensive University in the UK. Proceedings of the eMOOC summit, Switzerland, 259-264, 2014.

[17] SAMS, A. \& BERGMANN, J.: Flip Your Students' Learning. Educational Leadership, 70, 16-20, 2013.

[18] VENKATESH, V., MORRIS, M. G., DAVIS, G. B. \& DAVIS, F. D.: User Acceptance of Information Technology: Toward a Unified View. MIS Quarterly, 27(3), 425-478, 2003.

[19] JURJEWICZ, H.: Social Work, Youth Perception, Career Choice and Own Lived Experience Rapport from Empirical study based on States: New Jersey and New York. Charity Philanthropy and Social Work, Jaroslaw, 1, 81-93, 2015.

[20] CALDWELL, J. E.: Clickers in the Large Classroom: Current Research and Best-Practice Tips (pdf). CBE - Life Sciences Education, 6(1), 9-20, 2007.

[21] JURJEWICZ, H.: Social Work Methods \& Skills. Scientific Analysis and Practice based on the Experience Used in New Jersey and New York. Charity Philanthropy and Social Work, Jaroslaw, 1, 15-30, 2015.

[22] BLACK, P. \& WILIAM, D. Assessment and Classroom Learning [abstract]. Assessment in Education: Principles, Policy \& Practice, 5(1), 1998.

[23] JURJEWICZ, H.: Catholicism and Social Work: Integration of Catholic Faith and Social Work Practice Based On Experience of Social Workers in New Jersey and New York. Wartosci Chrzescijanskie w XX i XXI wieku zagrozenia i szanse, Regis, 156-167, 2015.

[24] BAK, T., JURJEWICZ, H. \& MIERZWA J.: Religion and Spirituality in Social Work Practice. New Jersey, p. 54, 2015 , q:117.

[25] SLIVKA, D.: Hebraic Scriptural Hermeneutics in the Ancient Hellenistic World as the Basic Approach of Early Christians. European Journal of Science and Theology, 11(5), 87-96, 2015.

[26] JURJEWICZ, H.: The Role of Psychology in Religion and Spirituality. New Jersey, 2014.

[27] GRACE, J. \& KENNY, C.: A Short Review of Information and Communication Technologies and Basic Education in Less Developed Countries - What is Useful, What is Sustainable? International Journal of Educational Development 23, 627-636, 2003; HASKOVA, A., MANDUlAKOVA, S., \& MERODE, D.: Problematic Aspects of Technology Education in Slovakia. Communications - Scientific Letters of the University of Zilina, 19(1), 75-80, 2017; ZAHOREC, J., HASKOVA, A., MUNK, M. \& BILEK, M.: Results of Pisa and Evaluation of Computer Science Education. Journal of Baltic Science Education, 12(2), 234-248, 2013. 